\title{
Combination treatment with photodynamic therapy and curcumin induces mitochondria-dependent apoptosis in AMC-HN3 cells
}

\author{
JIN-CHUL AHN ${ }^{1,2^{*}}$, JUNG-WOOK KANG ${ }^{1 *}$, JANG-IN SHIN $^{1,3}$ and PHIL-SANG CHUNG ${ }^{1,2}$ \\ ${ }^{1}$ Medical Laser and Device Research Center, ${ }^{2}$ Department of Otolaryngology, Head and Neck Surgery, College of Medicine, \\ ${ }^{3}$ Biosafety and Validation Center, Clinical Trial Institute, Dankook University, Cheonan 330-714, Republic of Korea
}

Received July 12, 2012; Accepted September 14, 2012

DOI: 10.3892/ijo.2012.1661

\begin{abstract}
Photodynamic therapy (PDT) is a treatment for the selective destruction of cancerous and non-neoplastic cells that involves the simultaneous presence of light, oxygen and a lightactivatable chemical known as a photosensitizer. Curcumin is one of the most extensively investigated phytochemicals with chemopreventive potential and antitumor effects. In this study, the effect of a combination of PDT and curcumin on apoptotic cell death in AMC-HN3 cells and the molecular mechanism underlying apoptosis was examined to confirm the interaction between photofrin-induced PDT and curcumin during combined mortality. The combination treatment with curcumin and PDT inhibited approximately $70 \%$ of the cell viability after PDT, whereas the PDT and curcumin only groups showed a 50 and $10 \%$ decrease in cell viability, respectively. In addition, the combination treatment increased the apoptotic events, such as nuclear fragmentation and nuclear condensation. This combination group showed an increase in ROS generation that was higher than that observed after each single treatment. Compared to the single agent treatments, the combination therapy induced the enhanced loss of $\Delta \psi_{\mathrm{m}}$. Furthermore, the cytosolic levels of cytochrome $c$ were significantly elevated in the combination group. Caspases-9, -3 and PARP, which are apoptosis-related proteins induced by mitochondrial activation, were upregulated remarkably by the combination treatment. When co-treated with glutathione, a singlet oxygen quencher, the combination treatment-induced synergistic cytotoxic and apoptotic effects, enhanced the generation of ROS and suppressed the upregulation of caspase- 3 and PARP. These results suggest that the combination modality with PDT and curcumin have a better treatment effect in vitro. The induction of mitochondrial-depen-
\end{abstract}

Correspondence to: Professor Phil-Sang Chung, Department of Otolaryngology, Head and Neck Surgery, College of Medicine, Dankook University, 29-1, Anseo-dong, Cheonan, Chungnam 330-714, Republic of Korea

E-mail: pschung@dankook.ac.kr

*Contributed equally

Key words: photodynamic therapy, curcumin, apoptosis, reactive oxygen species, cytochrome $c$ dent apoptosis due to the increased generation of ROS may be involved in this combination treatment.

\section{Introduction}

Photodynamic therapy (PDT) is a treatment for the selective destruction of cancerous and non-neoplastic cells that involves the simultaneous presence of light, oxygen and a light-activatable chemical known as a photosensitizer, with a photosensitive molecule that can be localized in the target cells (1). Photofrin, a representative of the first generation photosensitizers, is transformed by haematoporphyrin derivatives $(\mathrm{HpD})$ and absorbs light up to $640 \mathrm{~nm}$ (2). It is the most widely used photosensitizer in clinical PDT, and has been approved by health agencies to treat human solid malignancies (1). PDT has been indicated as a promising treatment for a wide range of cancers, such as cervical cancer and head and neck cancer (3-5). After PDT, the release of mitochondrial cytochrome $c$ into the cytosol leads to apoptosis (6), which is characterized by chromatin condensation, cleavage of chromosomal DNA into internucleosomal fragments, cell shrinkage, membrane blebbing, and the formation of apoptotic bodies without plasma membrane breakdown (6). Lu et al reported that methylene blue-mediated PDT induces mitochondria-dependent apoptosis in HeLa cells (7).

The photosensitizer transfers energy from light to molecular oxygen to generate reactive oxygen species (ROS), particularly singlet oxygen, hydroxyl radicals and peroxides. This photosensitizer can react with oxygen via energy transfer processes, generating singlet oxygen $\left({ }^{1} \mathrm{O}_{2}\right)$ or it can participate in electron transfer processes, leading to radical formation (8). Normally, direct and indirect evidence supports the prevalent role of ${ }^{1} \mathrm{O}_{2}$ in the molecular processes initiated by PDT (9). Both reactions can lead to damage to the cellular components and cell death by either apoptosis or necrosis. The apoptosis caused by ROS generated in HeLa cells by Hematoporphyrin monomethyl ether (HMME)-induced PDT was reported to be mediated by cytochrome $c$ release and caspase-3 activation (10).

Curcumin (1,7-bis(4-hydroxy-3-methoxyphenyl)-1,6heptadiene-3,5-dione), also known as diferuloymethane, is the major yellow pigment in turmeric (Curcuma longa) and is one of the most extensively studied phytochemicals with chemopreventive potential (11). Curcumin has been used in traditional Asian, Indian medicine for thousands of years to treat a range of diseases (12). Curcumin has antitumor properties in cancers of 
the breast (13), glioblastoma (14), head and neck (15), colon (16) and leukemia (17). The major mechanism by which curcumin induces cytotoxicity in tumor cells is the induction of apoptosis. Curcumin decreases the expression of anti-apoptotic members of the Bcl-2 family and elevates the expression of Bax, caspase-3, -8 and -9 . In addition, it induces apoptosis through the mitochondrial pathway involving the release of cytochrome $c$, and then activates PARP cleavage (18). Karmakar et al reported that curcumin activates caspases for apoptosis in human malignant glioblastoma U87MG cells (14).

Conventional cancer therapies, including PDT and chemotherapy as a single modality, have a limited but important role in the overall treatment of most solid tumors. Therefore, the strategies of cancer treatment using combined therapies are considered more promising for higher efficacy, resulting in better survival rates. Cancer therapies combining chemoprevention including curcumin may have enhanced antitumor activity with a decrease in the toxicity caused by PDT. Recent evidence suggests that the photosensitizer effect of curcumin on UVB-irradiated HaCaT cells occurs through activation of the caspase pathways (19). In addition, Dujic et al reported that low concentrations of curcumin induce apoptosis in skin keratinocytes only in combination with UVA or visible light (20).

In this study, to confirm the interaction between photofrininduced PDT and curcumin during combined mortality, this study examined effect and potential mechanism of a combination of PDT and curcumin on apoptotic cell death in AMC-HN3 cells.

\section{Materials and methods}

Reagents. Photofrin, a derivative of the haematoporphyrin, was purchased from LitePharm Tech, and was stable in PBS at $-20^{\circ} \mathrm{C}$ in the dark. Curcumin (Sigma, St. Louis, MO, USA) was stable in DMSO (Sigma). A total of $100 \mathrm{mM}$ of a stock solution of curcumin was stored at $-20^{\circ} \mathrm{C}$ in the dark. The following antibodies were used: anti-caspase- 8 (Calbiochem, La Jolla, CA, USA), anti-caspase-9 (Cell Signaling Technology, MA, USA), anti-capase-3 (Calbiochem), anti-cytochrome $c$ (BDBiosciences, Oxford, UK), anti-PARP (Santa Cruz Biotechnology, Santa Cruz, CA, USA), horseradish conjugated anti-mouse IgG (Santa Cruz Biotechnology) and horseradish conjugated anti-rabbit IgG (Santa Cruz Biotechnology).

Cell culture. The human head and neck cancer cell line (AMC-HN3) was kindly provided by Asan Medical Center (Seoul, Korea). The AMC-HN3 cells were cultured in RPMI-1640 medium (Hyclone, Logan, UT, USA) supplemented with $10 \%$ fetal bovine serum (FBS) (Hyclone) and $100 \mu \mathrm{g} / \mathrm{ml}$ streptomycin and $100 \mathrm{U} / \mathrm{ml}$ penicillin (Hyclone) at $37^{\circ} \mathrm{C}$ in a $5 \% \mathrm{CO}_{2}$ incubator.

Photodynamic therapy (PDT). The cells were seeded in 6-well plates, 96-well plates or plates, $100 \mathrm{~mm}$ in diameter. The cells were treated with a series of 2-fold dilutions of photofrin, starting at $50 \mu \mathrm{g} / \mathrm{ml}$ and incubated for $6 \mathrm{~h}$ at $37^{\circ} \mathrm{C}$ in a $5 \% \mathrm{CO}_{2}$ incubator. Subsequently, the photosensitized cells were irradiated with $630 \mathrm{~nm}$ diode laser $\left(0.83 \mathrm{~mW} / \mathrm{cm}^{2}\right)$ for $15 \mathrm{~min}$ at room temperature. After irradiation, the cells were incubated in a humidified atmosphere at $37^{\circ} \mathrm{C}$ and $5 \% \mathrm{CO}_{2}$ for the indicated times.
Cell viability. The MTT assay was used to assess the cell viability of AMC-HN3 cells after the combination treatment. The cells attached in a 96-well plate $(1,000$ cells/well) were treated with $25 \mu \mathrm{M}$ of curcumin for $6 \mathrm{~h}$. Subsequently, the cells were incubated with $3 \mu \mathrm{g} / \mathrm{ml}$ photofrin for $6 \mathrm{~h}$. The photosensitized cells were then irradiated with a $630 \mathrm{~nm}$ diode laser for $15 \mathrm{~min}$. The cells were then incubated for $24 \mathrm{~h}$ at $37^{\circ} \mathrm{C}$ in a $5 \% \mathrm{CO}_{2}$ incubator and exposed to MTT [3-(4,5-dimethylthiazol-2-yl)-2,5-diphenyltetrazolium bromide] ( $2 \mathrm{mg} / \mathrm{ml}$, Sigma) for $4 \mathrm{~h}$. The solution was changed to $150 \mu \mathrm{l}$ of dimethylsulfoxide (DMSO, Kanto, Japan). After 5-min incubation and shaking in microplate mixer (Amersham Pharmacia Biotech, Amersham, UK), the optical density (OD) was measured using a microplate reader (Bio-Rad, Hercules, CA, USA) at $540 \mathrm{~nm}$ wavelength. The cell viability was calculated using the following formula: Cell viability (\%) $=$ Mean optical density of treated wells/Mean optical density of control wells $\mathrm{x} 100$.

Detection of apoptosis and necrosis using Hoechst 33342 and propidium iodine (PI). Hoechst 33342 (Sigma) and PI (Sigma) double staining was used to identify the cell death pattern. The nuclear morphology was assessed with the cell membrane-permeant supravital DNA dye Hoechst 33342 (excitation wavelength, $348 \mathrm{~nm}$; emission, $479 \mathrm{~nm})$. Hoechst 33342, unlike PI, enters and stains the nucleus of both viable cells and cells with apoptosis or necrosis. The plasma membrane integrity was assessed using the cell membrane-impermeant DNA dye PI (excitation wavelength $535 \mathrm{~nm}$; emission $617 \mathrm{~nm}$ ). Necrosis was determined based on the positive PI staining in red color, which is indicative of a loss of membrane integrity (21). Briefly, $3 \mathrm{~h}$ after PDT, the cells were stained with Hoechst $33342(1 \mu \mathrm{g} / \mathrm{ml})$ for $30 \mathrm{~min}$. The medium was then changed and the cells were incubated with PI $(1 \mu \mathrm{g} / \mathrm{ml})$ for $10 \mathrm{~min}$ before the observations by confocal laser scanning microscopy (Carl Zeiss, Oberkochen, Germany).

Measurement of reactive oxygen species (ROS). The intracellular accumulation of ROS was determined using $\mathrm{H}_{2}$ DCFDA (2',7'-Dichlorodihydro fluorescein diacetate, Molecular Probes, Eugene, OR, USA), as previously described (22). Briefly, $1 \mathrm{~h}$ after PDT, the cells were incubated with $2 \mu \mathrm{M} \mathrm{H}_{2}$ DCFDA for 30 min and washed gently twice with DPBS. Images of green $\mathrm{H}_{2}$ DCFDA were collected by LSM-510-META confocal microscopy (Carl Zeiss) with an excitation wavelength of $488 \mathrm{~nm}$, a $560 \mathrm{~nm}$ dichroic mirror, and a 505 to $550 \mathrm{~nm}$ band pass barrier filter.

Mitochondrial membrane potential $\left(\Delta \psi_{m}\right)$. Rhodamine 123 (Molecular Probes) was used to evaluate the mitochondrial membrane potential $\left(\Delta \psi_{\mathrm{m}}\right)$, as predicted previously (22). Briefly, $2 \mathrm{~h}$ after PDT, the cells were re-suspended and loaded with $1 \mu \mathrm{M}$ rhodamine 123 for $30 \mathrm{~min}$. The signal for rhodamine 123 was detected by the FL1-H (530 nm) channel and the data were analyzed using the CELLQuest Program (Becton Dickinson, San Jose, CA, USA). At least 20,000 events were counted.

Protein extraction and western blot analysis. Six hours after PDT, the cells were washed twice with cold DPBS, and the cytosolic fraction and total protein were extracted in CE1 buffer (Qiagen, Valencia, CA, USA) and RIPA buffer, respec- 
A

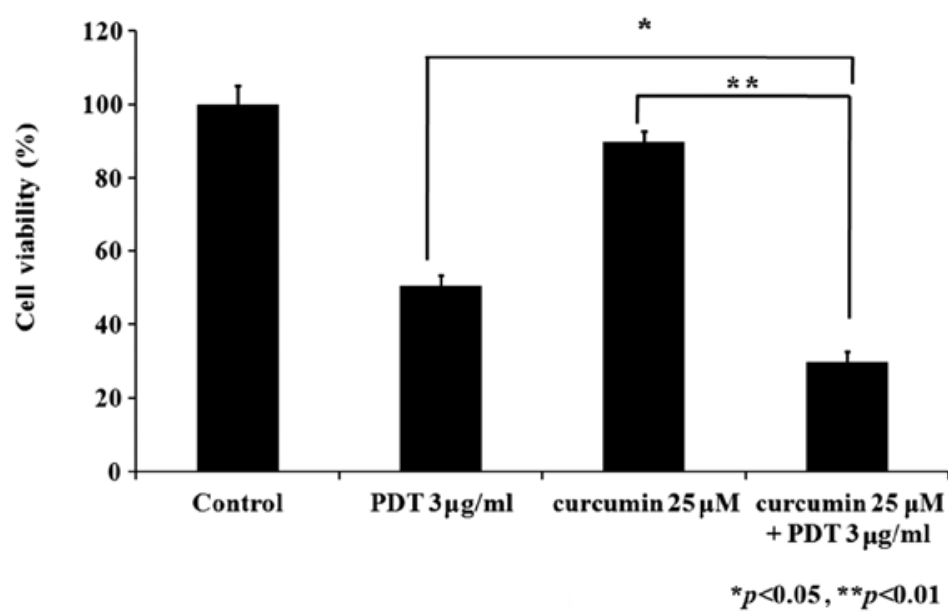

B

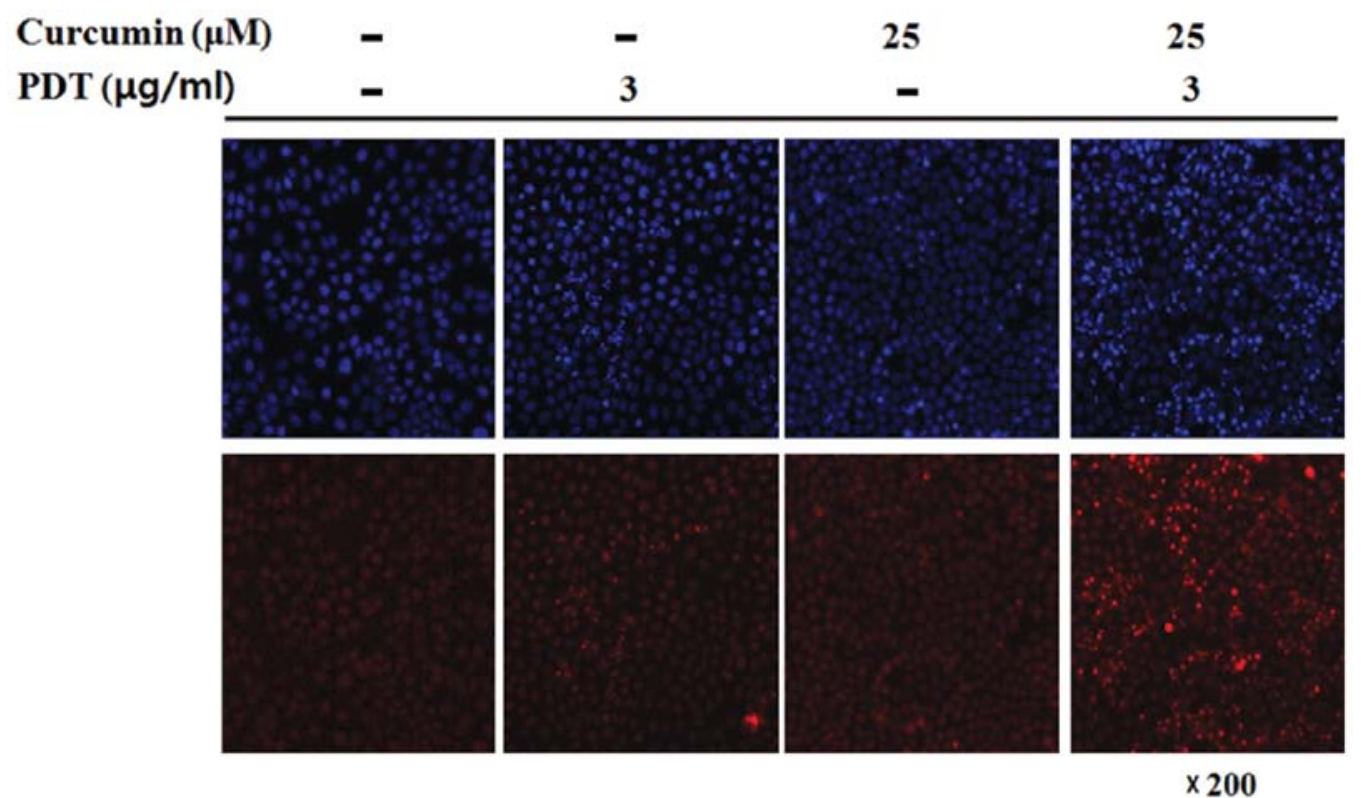

Figure 1. Curcumin combined with PDT induces cell proliferation and apoptosis. (A) The cells were treated with $25 \mu \mathrm{M}$ curcumin for $6 \mathrm{~h}$ and then with $3 \mu \mathrm{g} / \mathrm{ml}$ photofrin for $6 \mathrm{~h}$. The treated cells were irradiated with a $630-\mathrm{nm}$ laser $\left(0.83 \mathrm{~mW} / \mathrm{cm}^{2}\right)$ for $15 \mathrm{~min}$. After treatment, the cell viability was determined by MTT assay. Each value represents the mean \pm SD of three independent experiments. ${ }^{*} \mathrm{p}<0.05,{ }^{* *} \mathrm{p}<0.01$. (B) The cells were pretreated with or without curcumin. The cells were subjected to PDT and incubated with Hoechst $33342(1 \mu \mathrm{g} / \mathrm{ml})$ for $30 \mathrm{~min}$ and PI $(1 \mu \mathrm{g} / \mathrm{ml})$ for $10 \mathrm{~min}$. The morphological change in the cells was visualized by confocal microscopy. Magnification, x200.

tively. A Bradford assay (Bio-Rad) was used to determine the protein concentration by measuring the optical density at $595 \mathrm{~nm}$ using a spectrophotometer (Biochrom, Cambridge, UK). The protein samples were mixed with a $5 \mathrm{X}$ loading buffer (250 mM Tris, pH 6.8, 40\% glycerol, 4\% $\beta$-mercaptoethanol, $0.08 \%$ bromophenol blue, $8 \%$ sodium dodecyl sulfate), heatdenatured at $95^{\circ} \mathrm{C}$ for $10 \mathrm{~min}$, loaded onto the $10 \%$ sodium dodecyl sulfate polyacrylamide gel and at $100 \mathrm{~V}$ for $90 \mathrm{~min}$. After electrophoresis, gels with the resolved proteins were transferred to PVDF membranes (Bio-Rad) and blocked for $1 \mathrm{~h}$ in $10 \%$ skim milk. Each primary antibody (caspase-3, -9, cytochrome $c$ and PARP) was diluted in 5\% skim milk and added to the membrane for $90 \mathrm{~min}$. The membranes were washed five times with DPBS and detected with horseradish peroxidaseconjugated secondary IgG for $1 \mathrm{~h}$. The labeled protein bands were detected using a Kodak in vivo image analyzer (Eastern Kodak, Rochester, NY, USA).
Treatment with antioxidant. The attached cells were co-treated with $25 \mu \mathrm{M}$ of curcumin and either $40 \mathrm{mM}$ D-mannitol or $5 \mathrm{mM}$ glutathione for $6 \mathrm{~h}$. The cells were then incubated with $3 \mu \mathrm{g} / \mathrm{ml}$ photofrin in the presence of the individual antioxidant for $6 \mathrm{~h}$. After washing with fresh medium, the cells were subjected to irradiation under the aforementioned conditions.

Statistical analysis. The significance of the differences was evaluated using a Student's t-test. A p-value $<0.05$ was considered significant.

\section{Results}

Increase of cytotoxic and apoptotic effect. A MTT assay was used to measure the cytotoxicity $24 \mathrm{~h}$ after PDT to assess the combination effect of curcumin and photofrin-induced PDT on AMC-HN3 cells. As shown in Fig. 1A, curcumin alone and 
A
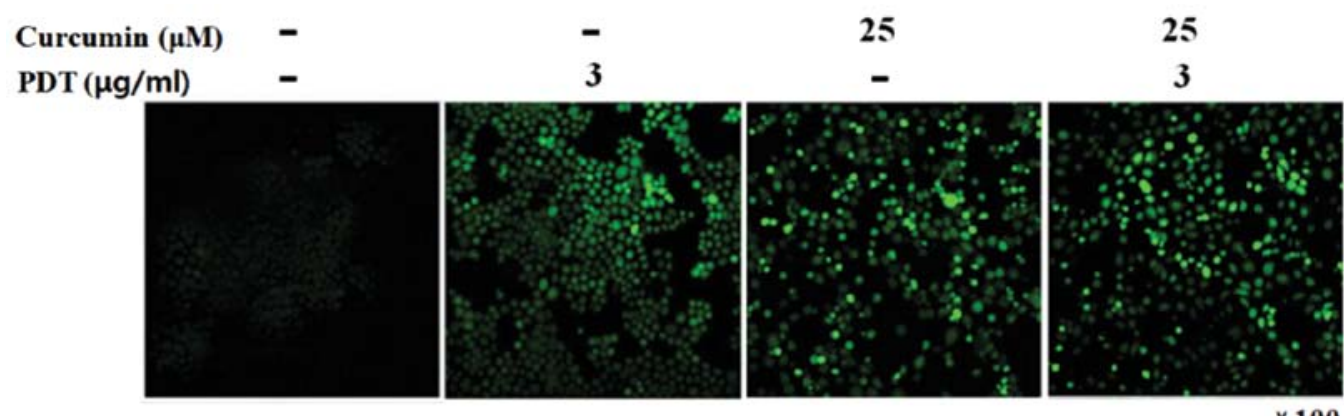

$\times 100$

B

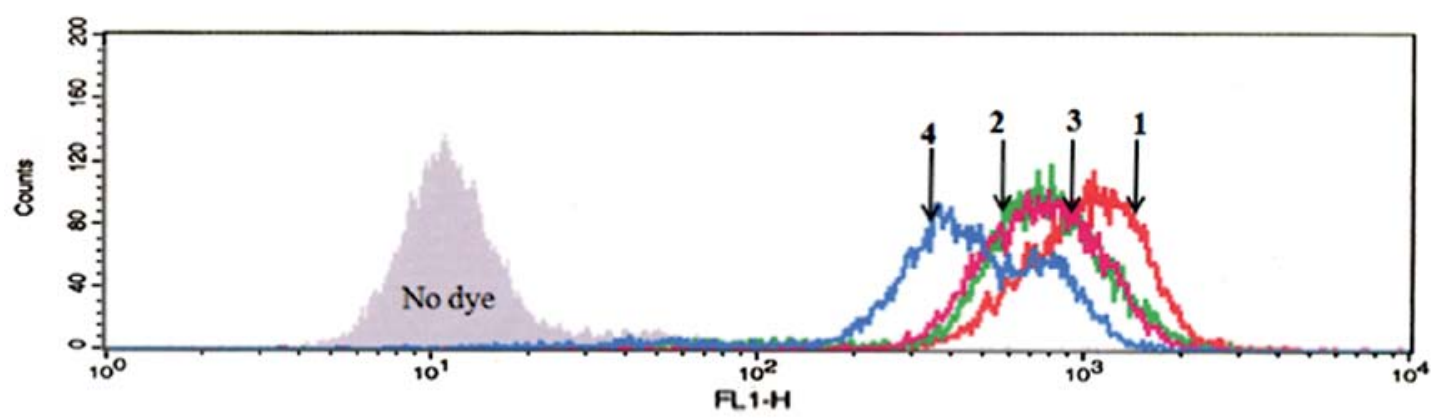

C

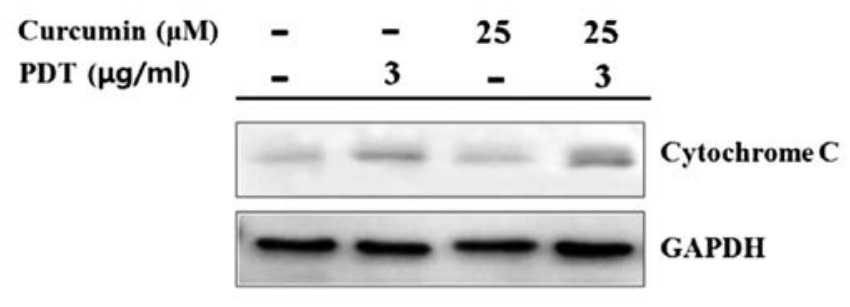

Figure 2. Curcumin combined with PDT changed mitochondria-induced ROS generation, collapse of MMP and cytochrome $c$ release. (A) The cells were washed with DPBS and incubated with $\mathrm{H}_{2}$ DCFDA $(10 \mu \mathrm{M})$ for $30 \mathrm{~min}$. ROS were measured by confocal microscopy. Magnification, x100. (B) The cells were treated with $3 \mu \mathrm{g} / \mathrm{ml}$ of photofrin and irradiated with a laser. The cells were then incubated for $2 \mathrm{~h}$ and stained with Rhodamine 123 (Molecular Probe) for $30 \mathrm{~min}$ at $37^{\circ} \mathrm{C}$. MMP was analyzed by flow cytometry. 1 , control; $2,25 \mu \mathrm{M}$ of curcumin; $3,3 \mu \mathrm{g} / \mathrm{ml}$ of PDT; $4,25 \mu \mathrm{M}$ curcumin and $3 \mu \mathrm{g} / \mathrm{ml}$ of PDT. (C) Cytosolic fraction $(80 \mu \mathrm{g})$ prepared $6 \mathrm{~h}$ after PDT was separated by $15 \%$ SDS-PAGE and then immunoblotted with anti-cytochrome $c$ antibody.

PDT alone, respectively, inhibited approximately 10 and 50\% of the cell viability, whereas a combination treatment with curcumin and photofrin-induced PDT inhibited approximately $70 \%$ of the cell viability. Dividing the effect from curcumin, there was an approximately $10 \%$ extra cytotoxic effect from the combination group comparing to the PDT only group.

Hoechst 33342 and PI double staining were performed to determine if the combination treatment induced enhanced apoptosis. There were only infrequent apoptotic bodies in curcumin only and PDT only groups. In contrast, more condensed/fragmented blue and pink nuclei as well as some pink intact nuclei were observed in the combination group. (Fig. 1B) This suggests that the combination treatment had a more intense apoptotic effect than each single treatment.

Changes of reactive oxygen species (ROS) generation, mitochondrial membrane potential $\left(\Delta \psi_{m}\right)$, and cytochrome $c$ release. To determine if a pretreatment with curcumin affects the generation of ROS by PDT, the intracellular ROS level was detected using the fluorescent probe $\mathrm{H}_{2}$ DCFDA, which is readily oxidized to 2',7'-dichlorofluorescein (DCF) in the presence of ROS. Compared to the control group, curcumin and PDT alone induced remarkable generation of ROS. The ROS signal induced by the combination group was higher than that of each single treatment (Fig. 2A).
To further examine the activation of mitochondria, the collapse of $\Delta \psi_{\mathrm{m}}$ was quantified by flow cytometry. Compared to the control group, a decrease in $\Delta \psi_{\mathrm{m}}$, a leftward shift in the fluorescence curve, was clearly observed in the curcumin or PDT treatment alone group. The combination group showed a more intense loss of $\Delta \psi_{\mathrm{m}}$ than that each single treatment group (Fig. 2B).

The collapse of $\Delta \psi_{\mathrm{m}}$ by PDT has been suggested to be a key factor in the release of cytochrome $c$ from the mitochondria to the cytosol. As shown in Fig. 2C, the release of cytochrome $c$ was increased markedly $6 \mathrm{~h}$ after PDT. Furthermore, a pretreatment with curcumin clearly enhanced the release of cytochrome $c$ from the mitochondria by PDT.

Increase of caspase-9, -3 and PARP activities by combination treatment. Mitochondrial release of cytochrome $c$ into the cytosol may lead to the activation of caspase- 9 and -3 for apoptosis. The level of caspase- 9 and caspase- 3 activation was determined to confirm the induction of mitochondrialmediated apoptosis. There was stronger expression of the cleaved form of caspase-9 as well as its downstream executioner caspase- 3 in the combination group than that in PDT or curcumin only groups (Fig. 3). PARP, as a native substrate of caspase-3, showed a similar expression pattern to cleaved caspase-3. 


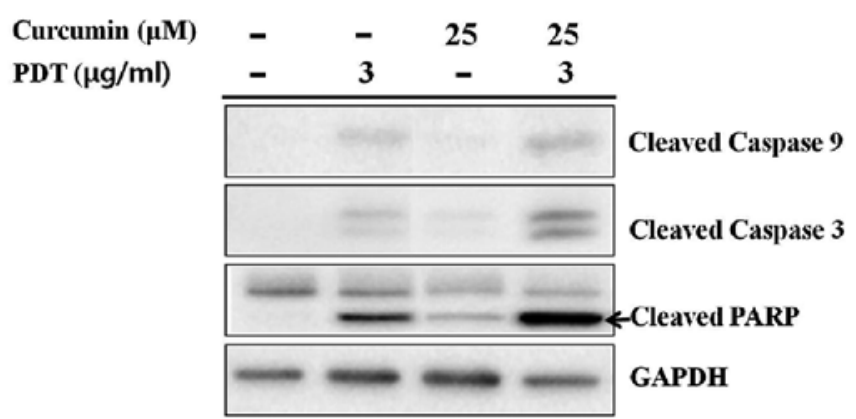

Figure 3. Curcumin combined with PDT activated caspase-9, -3 and PARP. The total proteins $(80 \mu \mathrm{M})$ were extracted and separated by $10 \%$ SDS-PAGE. The proteins were subjected to immunoblotting using anti-caspase antibodies and anti-PARP antibody, respectively.

Decrease of combination treatment induced ROS and cytotoxicity by glutathione. In Fig. 4A, the enhanced intracellular ROS levels of the combination treatment group were attenuated by glutathione (singlet oxygen quencher). As described above, the combination group exhibited a more intense cytotoxic effect than the single treatment groups. The decrease in cell viability induced by PDT and the combination group was prevented by glutathione (Fig. 4B), but not by D-mannitol (hydroxyl radical scavenger), indicating that singlet oxygen plays a key role in PDT and combination treatment. In the presence of glutathione, the cell survival rate was elevated by approximately 17 and $23 \%$ in the PDT only group and combination group, respectively.

Inhibition of apoptosis by glutathione. The mitochondriarelated apoptotic signals were investigated to further confirm the molecular mechanisms by which glutathione prevents apoptosis induced by the combination treatment. The collapse of $\Delta \psi_{\mathrm{m}}$ in the combination therapy group was protected by a concomitant treatment with glutathione (Fig. 5A). Similarly to the change in $\Delta \psi_{\mathrm{m}}$, the release of cytochrome $c$ also decreased in the combination therapy group with glutathione (Fig. 5B). Moreover, the expression of caspase-3 and PARP protein were inhibited by glutathione (Fig. 5C).

\section{Discussion}

PDT must provide an enhanced therapeutic response to be used as a first-line curative modality (23). Consequently, combination regimens consisting of PDT and a secondary treatment can be designed to increase the effectiveness of PDT. The systemic toxicity might be reduced due to the use of a lower dose of photosensitizer during combination PDT.
A
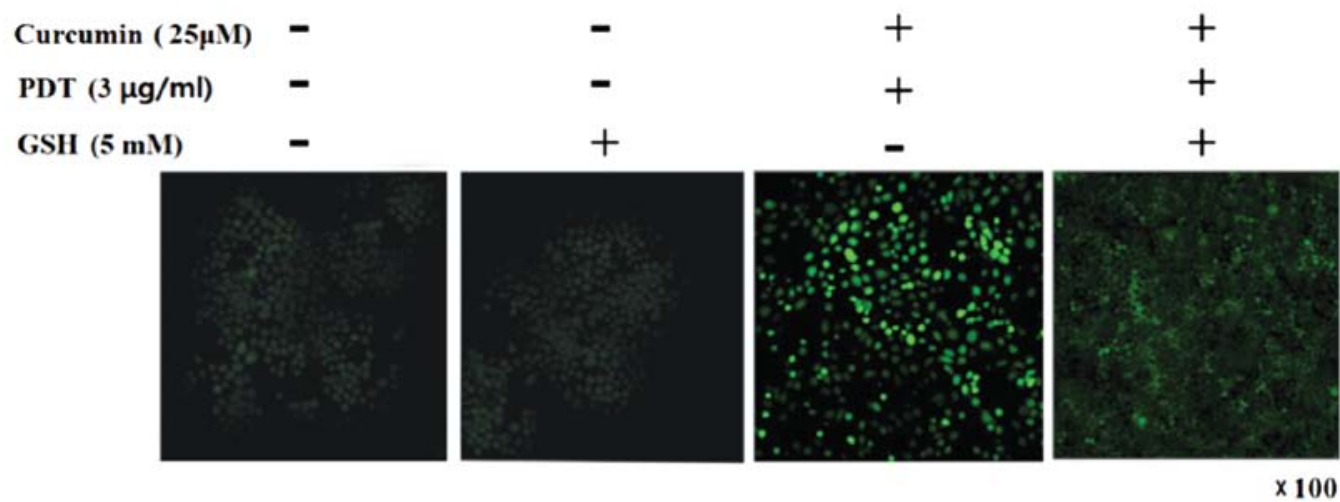

B

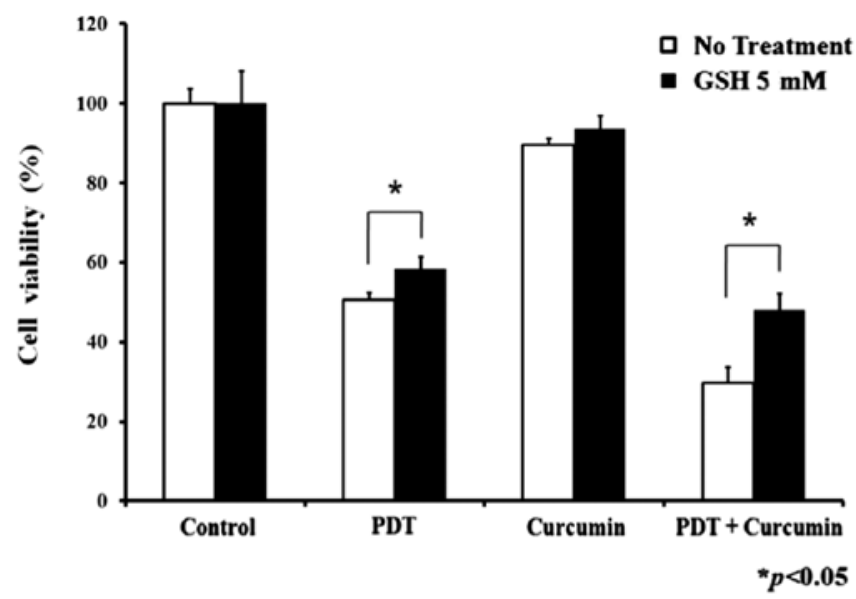

Figure 4. ROS generation and cytotoxicity induced by curcumin/PDT and the inhibitive effect of glutathione. (A) The cells were incubated with curcumin and glutathione for $6 \mathrm{~h}$, treated with photofrin and glutathione for $6 \mathrm{~h}$ and irradiated with a laser without glutathione. The levels of ROS were measured using confocal microscopy. Magnification, x100. (B) The cells were incubated with curcumin and glutathione and then treated with photofrin and glutathione. The treated cells were irradiated with a 630-nm laser for $15 \mathrm{~min}$ without glutathione. After treatment, the cell viability was determined using the MTT assay. Each value represents the mean $\pm \mathrm{SD}$ of three independent experiments. 
A

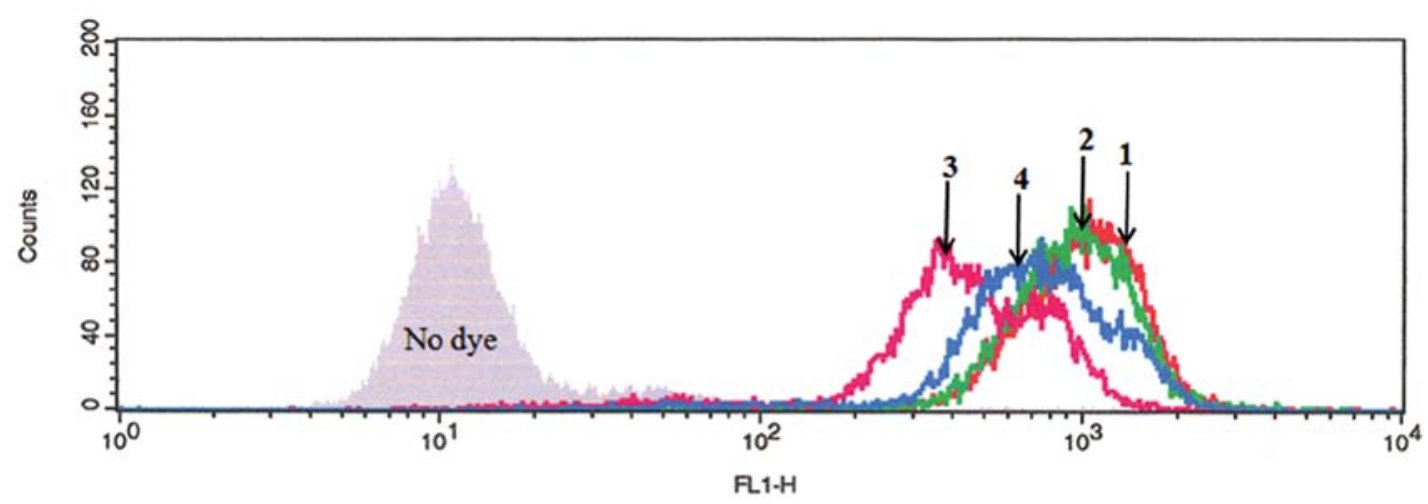

B

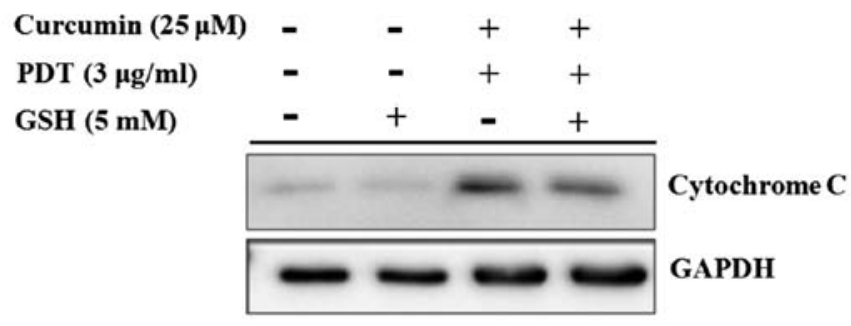

C

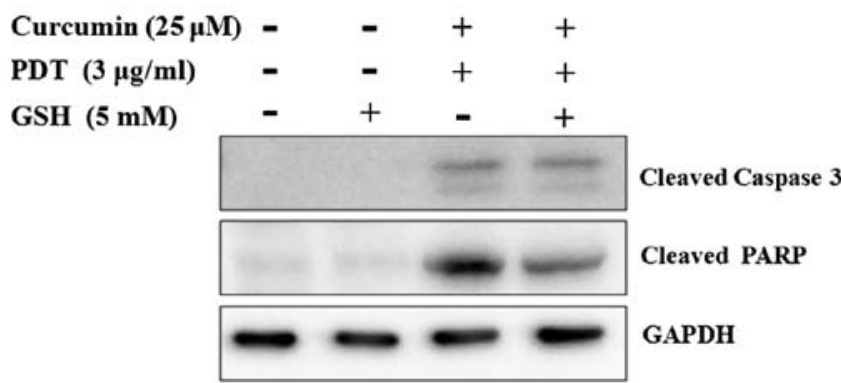

Figure 5. Effect of the singlet oxygen-specific inhibitor glutathione on the combination treatment-induced MMP collapse, cytochrome $c$ release, as well as the activation of caspase- 3 and PARP. (A) The cells were incubated with curcumin and glutathione for $6 \mathrm{~h}$, treated with $3 \mu \mathrm{g} / \mathrm{ml}$ of photofrin and glutathione for $6 \mathrm{~h}$, then irradiated by laser without glutathione. The treated cells were incubated at $2 \mathrm{~h}$. The cells were stained with Rhodamine 123 for 30 min at $37^{\circ} \mathrm{C}$. MMP was analyzed by flow cytometry. 1 , control; $2,5 \mathrm{mM}$ of glutathione; $3,25 \mu \mathrm{M}$ curcumin and $3 \mu \mathrm{g} / \mathrm{ml}$ of PDT, 4, $25 \mu \mathrm{M}$ curcumin, $3 \mu \mathrm{g} / \mathrm{ml}$ of PDT and $5 \mathrm{mM}$ of glutathione. (B) The cells were treated with combination therapy or glutathione. Cytosolic fraction ( $80 \mu \mathrm{g})$ was separated by $15 \%$ SDS-PAGE and then immunoblotted with the anti-cytochrome $c$ antibody. (C) The cells were treated with combination therapy or glutathione. The total proteins ( $80 \mu \mathrm{M})$ were extracted and separated by $10 \%$ SDS-PAGE. The proteins were subjected to immunoblotting using the anti-caspase-3 and anti-PARP antibody, respectively.

The strategies of cancer treatment using combined therapies or combined agents with distinct molecular mechanisms are considered to be more promising for higher efficacy in the induction of apoptosis. The number of publications regarding the potentiated antitumor effects of cancer therapies using the chemopreventive agent, curcumin, has increased dramatically. In addition, common cancer therapies combined with these dietary compounds may exert enhanced antitumor activity through synergistic action (24).

Curcumin can both stimulate and inhibit apoptotic signaling. For example, curcumin induces apoptosis in human melanoma cells (30-60 $\mu \mathrm{M}$ for $24 \mathrm{~h}$ ) (25), whereas recent studies reported that curcumin attenuates UV irradiation-induced ROS formation and apoptosis in epidermoid carcinoma A431 cells (25-50 $\mu \mathrm{M}$ for 2-3 h) (26), and prevents PDT-induced cell death (27). In this study, curcumin alone decreased the cell viability of AMC-HN-3 cells in a dose- and time-dependent manner (data not shown). The curcumin plus PDT group showed an increased cytotoxic effect compared to each single group (Fig. 1A).

Fig. 1B shows infrequent apoptotic bodies in both the low concentration of PDT ( $3 \mu \mathrm{g} / \mathrm{ml})$ and curcumin alone groups. On the other hand, the combination group induced more apoptotic cells with typical chromatin condensation, nuclear fragmentation, and the formation of apoptotic bodies (Fig. 1B). This suggests that the combination treatment initiated a more intense apoptotic effect than that of each single treatment group.
The mitochondria are a major source of ROS in cells. As reported, ROS play an important role in controlling a range of cell functions, such as proliferation and apoptosis (28). In the apoptosis-inducing concentrations, confocal microscopy analysis using the cell permeable dye $\mathrm{H}_{2}$ DCFDA as an indicator of ROS generation showed that the intracellular oxidative stress caused by single treatments were further enhanced by the combination therapy (Fig. 2A). The generation of ROS peaked at $1 \mathrm{~h}$ after PDT; the signal of which subsequently decreased later, indicating that ROS formation is transient.

Loss of the mitochondrial membrane potential $\left(\Delta \psi_{\mathrm{m}}\right)$ is associated with a dysfunction of the mitochondria, which can be detected in apoptotic cell death (29). Previous studies reported that the mitochondria are the targets of photodamage triggered by photofrin-PDT (30). Biochemical analysis indicated that $\mathrm{HpD} /$ photofrin PDT caused mitochondrial damage and inactivation of the mitochondrial enzymes (31). Lam et al suggested that PDT with Pc 4 triggers mitochondrial ROS production resulting in inner membrane permeablization, mitochondrial depolarization and swelling, which in turn leads to cytochrome $c$ release and apoptotic death (32). In this study, the induction of ROS by curcumin or PDT alone was consistent with the disruption of $\Delta \psi_{\mathrm{m}}$ after treatment (Fig. 2B). Compared with the single treatments, the combination group caused a more intense decrease in $\Delta \psi_{\mathrm{m}}$ and a much larger release of cytochrome $c$ from the mitochondria to the cytosol (Fig. 2C). 
Caspases play critical roles in the initiation and execution of apoptosis and are activated by cytochrome $c$ (33). In the present study, the combination group showed stronger caspase-9, -3 and PARP activation than those in the single treatment groups (Fig. 3).

Hydroxyl radical and singlet oxygen have been reported to be important cellular mediators for PDT-induced responses (34). The generation of intracellular ROS initiated by the combination group was suppressed by glutathione (Fig. 4A). D-mannitol, hydroxyl radical scavenger, had no protective effect on cell death induced by the single treatment groups or the combination group. However, the cell viability induced by the single or combination groups was protected by the co-treatment of glutathione (singlet oxygen quencher) (Fig. 4B). This suggests that singlet oxygen plays an important role in curcumin/photofrin-PDT-induced cytotoxicity. Glutathione also inhibited the combination therapyinduced $\Delta \psi_{\mathrm{m}}$ collapse (Fig. 5A) and cytochrome $c$ release by suppressing the generation of ROS (Fig. 5B). The upregulation of caspase- 3 and PARP by the combination group was prevented by glutathione (Fig. 5C).

In summary, these results suggest that the combined PDT with curcumin has enhanced cytotoxic and apoptotic effects on AMC-HN3 cells via a mitochondria-dependent apoptosis pathway. In addition, the generation of ROS plays an important role in this combination therapy-induced apoptosis.

\section{Acknowledgements}

We would like to thank the Medical Laser Research Center, Dankook University for the financial support.

\section{References}

1. Dougherty TJ, Gomer CJ, Henderson BW, et al: Photodynamic therapy. J Natl Cancer Inst 90: 889-905, 1998.

2. Saczko J, Mazurkiewicz M, Chwilkowska A, et al: Intracellular distribution of Photofrin in malignant and normal endothelial cell lines. Folia Biol (Praha) 53: 7-12, 2007.

3. Hopper C: Photodynamic therapy: a clinical reality in the treatment of cancer. Lancet Oncol 1: 212-219, 2000.

4. Yamaguchi S, Tsuda H, Takemori M, et al: Photodynamic therapy for cervical intraepithelial neoplasia. Oncology 69: 110-116, 2005

5. Copper MP, Triesscheijn M, Tan IB, Ruevekamp MC and Stewart FA: Photodynamic therapy in the treatment of multiple primary tumours in the head and neck, located to the oral cavity and oropharynx. Clin Otolaryngol 32: 185-189, 2007.

6. Buytaert E, Dewaele M and Agostinis P: Molecular effectors of multiple cell death pathways initiated by photodynamic therapy. Biochim Biophys Acta 1776: 86-107, 2007.

7. Lu Y, Jiao R, Chen X, Zhong J, Ji J and Shen P: Methylene blue-mediated photodynamic therapy induces mitochondriadependent apoptosis in HeLa cell. J Cell Biochem 105: 1451-1460, 2008.

8. Moor AC: Signaling pathways in cell death and survival after photodynamic therapy. J Photochem Photobiol B 57: 1-13, 2000.

9. Niedre M, Patterson MS and Wilson BC: Direct near-infrared luminescence detection of singlet oxygen generated by photodynamic therapy in cells in vitro and tissues in vivo. Photochem Photobiol 75: 382-391, 2002.

10. Ding X, Xu Q, Liu F, et al: Hematoporphyrin monomethyl ether photodynamic damage on HeLa cells by means of reactive oxygen species production and cytosolic free calcium concentration elevation. Cancer Lett 216: 43-54, 2004.

11. Surh YJ: Cancer chemoprevention with dietary phytochemicals. Nat Rev Cancer 3: 768-780, 2003.

12. Rahman I, Biswas SK and Kirkham PA: Regulation of inflammation and redox signaling by dietary polyphenols. Biochem Pharmacol 72: 1439-1452, 2006.

13. Choudhuri T, Pal S, Agwarwal ML, Das T and Sa G: Curcumin induces apoptosis in human breast cancer cells through p53-dependent Bax induction. FEBS Lett 512: 334-340, 2002.
14. Karmakar S, Banik NL and Ray SK: Curcumin suppressed antiapoptotic signals and activated cysteine proteases for apoptosis in human malignant glioblastoma U87MG cells. Neurochem Res 32: 2103-2113, 2007.

15. Aggarwal S, Takada Y, Singh S, Myers JN and Aggarwal BB: Inhibition of growth and survival of human head and neck squamous cell carcinoma cells by curcumin via modulation of nuclear factor-kappaB signaling. Int J Cancer 111: 679-692, 2004.

16. Rashmi R, Kumar S and Karunagaran D: Human colon cancer cells lacking Bax resist curcumin-induced apoptosis and Bax requirement is dispensable with ectopic expression of Smac or downregulation of $\mathrm{Bcl}-\mathrm{XL}$. Carcinogenesis 26: 713-723, 2005.

17. Liu HL, Chen Y, Cui GH and Zhou JF: Curcumin, a potent anti-tumor reagent, is a novel histone deacetylase inhibitor regulating B-NHL cell line Raji proliferation. Acta Pharmacol Sin 26: 603-609, 2005.

18. Shishodia S, Chaturvedi MM and Aggarwal BB: Role of curcumin in cancer therapy. Curr Probl Cancer 31: 243-305, 2007.

19. Park K and Lee JH: Photosensitizer effect of curcumin on UVB-irradiated $\mathrm{HaCaT}$ cells through activation of caspase pathways. Oncol Rep 17: 537-540, 2007.

20. Dujic J, Kippenberger S, Hoffmann S, et al: Low concentrations of curcumin induce growth arrest and apoptosis in skin keratinocytes only in combination with UVA or visible light. J Invest Dermatol 127: 1992-2000, 2007.

21. Dursun B, He Z, Somerset H, Oh DJ, Faubel S and Edelstein CL: Caspases and calpain are independent mediators of cisplatininduced endothelial cell necrosis. Am J Physiol Renal Physiol 291: F578-F587, 2006.

22. Chung PS, He P, Shin JI, Hwang HJ, Lee SJ and Ahn JC: Photodynamic therapy with 9-hydroxypheophorbide alpha on AMC-HN-3 human head and neck cancer cells: induction of apoptosis via photoactivation of mitochondria and endoplasmic reticulum. Cancer Biol Ther 8: 1343-1351, 2009.

23. Gomer CJ, Ferrario A, Luna M, Rucker N and Wong S: Photodynamic therapy: combined modality approaches targeting the tumor microenvironment. Lasers Surg Med 38: 516-521, 2006.

24. Sarkar FH and Li YW: Targeting multiple signal pathways by chemopreventive agents for cancer prevention and therapy. Acta Pharmacol Sin 28: 1305-1315, 2007.

25. Bush JA, Cheung KJ Jr and Li G: Curcumin induces apoptosis in human melanoma cells through a Fas receptor/caspase-8 pathway independent of p53. Exp Cell Res 271: 305-314, 2001.

26. Chan WH, Wu CC and Yu JS: Curcumin inhibits UV irradiationinduced oxidative stress and apoptotic biochemical changes in human epidermoid carcinoma A431 cells. J Cell Biochem 90: 327-338, 2003.

27. Chan WH and Wu HJ: Anti-apoptotic effects of curcumin on photosensitized human epidermal carcinoma A431 cells. J Cell Biochem 92: 200-212, 2004.

28. Thannickal VJ and Fanburg BL: Reactive oxygen species in cell signaling. Am J Physiol Lung Cell Mol Physiol 279: L1005-L1028, 2000.

29. Hirsch T, Marchetti P, Susin SA, et al: The apoptosis-necrosis paradox. Apoptogenic proteases activated after mitochondrial permeability transition determine the mode of cell death. Oncogene 15: 1573-1581, 1997.

30. Kinzler I, Haseroth E, Hauser C and Ruck A: Role of mitochondria in cell death induced by Photofrin-PDT and ursodeoxycholic acid by means of SLIM. Photochem Photobiol Sci 6: 1332-1340, 2007.

31. Roberts WG, Liaw LH and Berns MW: In vitro photosensitization II. An electron microscopy study of cellular destruction with mono-L-aspartyl chlorin e6 and photofrin II. Lasers Surg Med 9: 102-108, 1989.

32. Lam M, Oleinick NL and Nieminen AL: Photodynamic therapy-induced apoptosis in epidermoid carcinoma cells. Reactive oxygen species and mitochondrial inner membrane permeabilization. J Biol Chem 276: 47379-47386, 2001.

33. Budihardjo I, Oliver H, Lutter M, Luo X and Wang X: Biochemical pathways of caspase activation during apoptosis. Annu Rev Cell Dev Biol 15: 269-290, 1999.

34. Price M, Terlecky SR and Kessel D: A role for hydrogen peroxide in the pro-apoptotic effects of photodynamic therapy. Photochem Photobiol 85: 1491-1496, 2009. 